\title{
Multispectral satellite imagery to quantify in-field soil moisture variability
}

\author{
J. Siegfried, L. Longchamps, and R. Khosla
}

\begin{abstract}
As pressure on available water resources increases, the need to exploit technology in order to produce more food with less water becomes crucial. The technological hardware requisite for precise water delivery methods, such as variable rate irrigation, is commercially available. Despite that, techniques to formulate a timely, accurate prescription for those systems are inadequate. Spectral vegetation indices are often used to gauge crop vigor and related parameters (e.g., leaf nitrogen $[\mathrm{N}]$ content). However, research heretofore rarely addresses the influence of soil moisture on the indices. The objectives of this study were to determine (1) if vegetation indices derived from multispectral satellite imagery could assist in quantifying soil moisture variability in irrigated maize (Zea mays L.) production, and (2) the period of time that a single image is representative of soil moisture. A variable rate irrigation pivot was used to form six water treatment zones. Each was equipped with tensiometers installed in the center of the plots at 20,45 , and $75 \mathrm{~cm}$ depths to individually monitor conditions in the water treatment zones. Water was applied for each treatment as a percentage of the estimated evapotranspiration (ET) requirement: 40\%, 60\%, 80\%, 100\%, 120\%, and 140\%. Data collected from tensiometers was paired with the image pixels corresponding to its ground location. Statistical analysis was performed separately to assess whether vegetation indices are representative of soil moisture at several crop growth stages. Findings from this study indicate that Red Edge Normalized Difference Vegetation Index could quantify soil moisture tension variability atV6 (six leaf; $r^{2}=0.850, p=0.009$ ) andV9 (nine leaf; $r^{2}=0.913, p=0.003$ ) crop growth stages Results suggest that satellite-derived vegetation indices may be useful for creating time-sensitive characterizations of soil moisture variability. Further study is necessary to investigate additional crop growth stages, more crops, and other sources of multispectral imagery.
\end{abstract}

Key words: irrigation-Normalized Difference Vegetation Index (NDVI)—red edgeremote sensing — soil moisture - variable rate irrigation

\begin{abstract}
Agriculture places a heavy burden on available water resources. In the United States, irrigation systems utilize about $80 \%$ of the available freshwater (Lea-Cox 2012). Heightened water demand from nonagriculture sectors is expected to increase overall water demand and pressure on water resources. More efficient irrigation systems in the western states have previously contributed to decreases in water application: although irrigated area increased by 850,000 ha between the years 1984 and 2008, agricultural water applications were reduced by over 120 million $\mathrm{m}^{3}$ (Schaible and Aillery 2012). These efficient irrigation systems, such as center-pivots and linear-move systems, can be exploited to further reduce water usage
\end{abstract}

Evans et al. (1996) identified defining and formulating a prescription for precision water application as the foremost problem for researchers to address. More specifically, the aforementioned authors suggested that "identification and quantification of contributing factors and their interactions that influence a real-time prescription are difficult." Continually changing conditions are likely to make decision algorithms highly temporally dependent, and techniques commonly used today to formulate water prescriptions - such as electrical conductivity-do not directly account for temporal variability. Longchamps et al. (2015) document that spatial and temporal variability in soil moisture content is significant even in precision leveled fields. Sadler et al. (2005) conclude that the inconsistent, highly dynamic nature of actual field circumstances probably necessitates strategically placed sensors to monitor soil moisture and micrometeorological variability in real time. Siegfried et al. (2017) suggest that inexpensive infrared thermometers could be used to gauge in-field soil moisture variability.

For decades, spectral vegetation indices have been employed to remotely monitor crops and other vegetation. While the spectral response of a crop can be used to identify the presence of stress, vegetation indices have the potential to function as surrogate measurements of the severity of that stress at multiple time points.

The red edge, a narrow portion of wavelengths (about 680 to $730 \mathrm{~nm}$ ) between the red and near-infrared regions of the electromagnetic spectrum, could improve on traditional broadband sensors to enhance the quality of information derived from multispectral satellite imagery because of its greater sensitivity to stress, which manifests as an early decrease in chlorophyll content in the plant canopy (Carter and Miller 1994). The rapid change in leaf reflectance characterized within the red edge makes it particularly useful for early stress detection. One example of a satellite platform mak-

Jeff Siegfried is a graduate research assistant at Colorado State University, Fort Collins, Colorado. Louis Longchamps is a research scientist of precision horticulture at Agriculture and Agri-Food Canada, Quebec, Canada. Raj Khosla is a Robert E. Gardner professor of precision agriculture at Colorado State University, Fort Collins, Colorado. 
ing use of the red edge is the RapidEye Satellite Constellation (BlackBridge, Berlin, Germany), which captures the red edge region between 690 to $730 \mathrm{~nm}$. This may be used as a more plant-sensitive replacement for the conventional red band in broadband vegetation index calculations, but few agricultural studies have investigated it.

Advances in technology have made remote sensing data vastly more available. Until the beginning of the second millennium, aerial imagery was the prevailing source of remote sensing for agricultural interpretation (Lillesand et al. 2008). However, improvements in both spatial and temporal resolution, along with rapid data availability, have drastically increased the use of satellite imagery for precision agriculture. These benefits could potentially be used to monitor in-field variability of plant water stress at a large scale (e.g., an entire section equipped with sprinkler irrigation), and thus inform precision irrigation systems. Utilizing the information available from remote sensing is an important challenge for irrigated agriculture, as water resource managers rarely take advantage of numerous remote sensing opportunities (Bastiaanssen et al. 2000).

Few studies exist that have addressed the use of multispectral data for monitoring soil water content, and those typically rely on shortwave infrared, microwave, thermal data, or estimate crop coefficients (Clarke 1997; Engman 1991; Li et al. 2001; Neale et al. 2005). Previous researchers were limited by low spatial resolution imagery, which was impractical for field-scale analysis (Adegoke and Carleton 2002). With increasing focus on precision agriculture and the advent of precision variable rate irrigation systems, it is important to investigate whether plant water stress can be characterized at large field scales using readily available, high spatial resolution data. Therefore, the objectives of this study were to determine (1) if vegetation indices derived from multispectral satellite imagery could quantify soil moisture tension variability in an irrigated maize (Zea mays L.) production system, and (2) the period of time that a single satellite image is representative of the variability.

\section{Materials and Methods}

Study Site. This experiment was conducted over the 2015 maize growing season at a site located north of Fort Collins in northeastern Colorado $\left(40.666^{\circ} \mathrm{N}, 104.998^{\circ} \mathrm{W}\right)$. The 12 ha field has been cultivated for many years under a continuous maize cropping system, conventional tillage, and furrow irrigation until 2012, when it was precision leveled and a center-pivot sprinkler system was installed.The soil series is Kim loam, which is characterized as very deep, moderately permeable, and is classified as fine-loamy, mixed, active, calcareous, mesic Ustic Torriorthents (Soil Survey Staff 1980). Slope at this site is between $1 \%$ and $3 \%$, and the climate is semiarid with an average annual precipitation of about $40 \mathrm{~cm}$. The field was seeded with eastwest rows on May 27, 2015, with DEKALB DKC46-20VT3 at a population of 93,900 plants ha ${ }^{-1}$

Experimental Procedure. A Valley variable rate irrigation pivot (Valmont Industries, Valley, Nebraska) was utilized to form six water treatment zones. Each zone was equipped with Hortau tensiometers (Hortau Simplified Irrigation, Lévis, Québec, Canada) installed in the center at 20,45, and $75 \mathrm{~cm}$ depths. Water was applied for each treatment as a percentage of the estimated evapotranspiration (ET) requirement: $40 \%, 60 \%, 80 \%, 100 \%$, $120 \%$, and $140 \%$. The depth of water applied at those rates corresponds to 20, 30, 41, 51, 61 , and $71 \mathrm{~cm}$ for the entire growing season, respectively. Estimated ETc requirements, or the amount needed to replenish water used by the plants and lost to evaporation, are based on weather conditions, such as solar radiation, wind speed, and humidity. For information on calculating crop water requirements, refer to Allen et al. (1998). The data and more details on the water requirement calculations are available at www.CoAgMET.ColoState. edu. To ensure that each treatment completely surrounded the tensiometers, the treatment zones were created three times larger than the area over which the pivot could accurately adjust the water application depth. Each individual treatment zone was about $325 \mathrm{~m}^{2}$ in size. To address the possibility of surface runoff, straw wattles were fixed at susceptible locations (figure 1).

The tensiometers were configured to upload data to server storage at 15 minute intervals throughout the growing season. Raw tension data were then downloaded from the web. On multiple occasions during the growing season, the tensiometer water reservoirs became depleted and required rehydration. This process generated data points not representative of actual soil moisture conditions. The date and time were noted for each rehydration event. The period between sensor dehydration and 24 hours after hydration was removed from the data. The return to normal sensor behavior was confirmed by viewing a plot of surrounding data points.

Orthorectified imagery from the RapidEye satellite constellation was provided by FarmLogs (FarmLogs, Ann Arbor, Michigan). The imagery product included radiometric, geometric, and terrain corrections by BlackBridge. The radiometric resolution is 12-bit with spatial resolution of $5 \mathrm{~m}$ and a revisit time of 5.5 days. The spectral bands are outlined in table 1 . The nine spectral vegetation indices examined were calculated using the formulae defined in table 2.

Data Analysis. An average soil tension was calculated for each irrigation treatment (40\% to $140 \%$ of estimated ET requirement) over three temporal periods prior to the satellite image acquisition dates: one day (96 soil tension measurements), one week (672 soil tension measurements), and the entire interval between planting and image acquisition $(>1,000$ soil tension measurements). Those averages were paired with vegetation index values, which were extracted from the satellite images using georeferenced points and geographic information system (GIS) software in order to obtain the pixel values corresponding to the actual ground location of the tensiometers. Points used for this process were acquired with a Trimble Ag114 DGPS receiver (Trimble Navigation Limited, Sunnyvale, California) equipped with OmniSTAR virtual base station (VBS) correction service (OmniSTAR, Houston, Texas).

Ordinary least squares regression of soil tension on vegetation indices was performed using the $\mathrm{R}$ software environment ( $\mathrm{R}$ Core Team 2015). To determine whether vegetation indices derived from multispectral satellite imagery could quantify soil moisture tension, three time intervals prior to each image acquisition were evaluated: average from (1) the previous day, (2) previous week, and (3) from planting to image acquisition date. This was done to assess the sensitivity of the satellite-derived indices to immediate, short-term, and long-term soil moisture variability, respectively. Results presented below are therefore grouped by these time intervals. All combinations of vegetation indices and tension averages were analyzed independently for all the satellite images, which 


\section{Figure 1}

Variable rate irrigation grid used for the center pivot at Colorado State University Agricultural Research Development and Education Center. Irrigation treatments are represented as filled cells. A different shade designates each zone and includes a point for the tensiometer locations, which are labeled with the percentage of estimated evapotranspiration (ET) used to calculate irrigation requirements for this study in 2015.

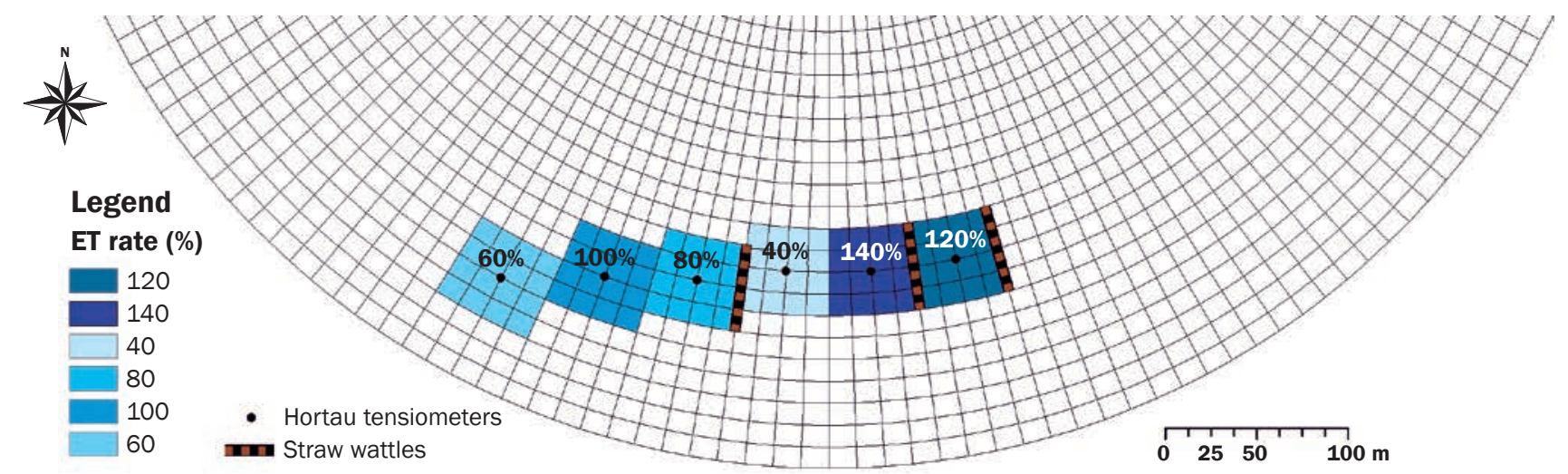

were acquired at two leaf, six leaf, nine leaf, and milk (R3) growth stages (table 3 and figure 2). In addition, an image acquired shortly after crop emergence (bare soil) was also analyzed. Statistical significance was determined using the Student's t-test.

\section{Results and Discussion}

The month of May was especially wet during the 2015 growing season, receiving more than double the historical average precipitation and contributing to above average annual precipitation (Western Regional Climate Center 2015). These conditions delayed planting by several weeks. The beginning of May is conventional timing for planting, but the maize was planted on May 27 for the 2015 season. See figure 3 for daily precipitation and irrigation events.

The relationship between vegetation indices and in-field soil moisture tension was studied at three soil depths where soil moisture tension readings were recorded throughout the growing season. For ease of understanding, the results are presented separately for each time period of soil moisture tension measurement: 24 hours, 1 week, and planting to image acquisition date.

Average Soil Tension from the Previous Day. Regression analysis of soil tension averaged over the day previous to image acquisition on the selected indices produced several noteworthy results (table 4). Red Edge Normalized Difference Vegetation Index (RENDVI) performed best with strong negative linear relationships at both V6 and V9 crop growth stages at $20 \mathrm{~cm}$ deep. The strong relationship between satellite imagery and 24-hour average soil tension may potentially be explained by short-term plant physiological response to drought stress, such as erect orientation of leaves, leaf rolling, and graying of tissue that would be detectable by satellite imagery. As shown in figure $4 \mathrm{a}$, functions for both models at this depth were very similar: the slopes were almost identical-less than $2 \%$ difference-and the intercept increased almost proportionally from the V6 to V9 growth stage. This indicates that images not only capture immediate soil moisture variability at separate growth stages, but also that a single image could be relatively representative of soil moisture variability between image acquisitions - perhaps up to a couple weeks, as with this study. In other words, an image could be used to help inform variable rate irrigation systems a few weeks after it was initially acquired by the satellite. This is especially important since irrigation water often is not immediately available, and satellite revisit times may not be convenient for management. Additionally, RENDVI was moderately correlated at the R3 growth stage at the $75 \mathrm{~cm}$ depth.

Red Edge Chlorophyll Index (RECI) also produced significant models with good relationships for V6 and V9 crop growth stages at $20 \mathrm{~cm}$ deep (figure $4 \mathrm{~b}$ ). In this case, the functions between the two differed considerably, and the coefficients of determination, although still very strong, indicated weaker correlations. It appears that RECI is less sensitive to changing soil water content, so the imagery did not show potential for extended postacquisition utility, as was the case with RENDVI, for which the equations over the V6 and V9 growth stages were quite similar.

\section{Table 1}

Spectral bands for the RapidEye Satellite Constellation (Planet 2016).

\begin{tabular}{ll}
\hline Name & Range $(\mathbf{n m})$ \\
\hline Blue & 440 to 510 \\
Green & 520 to 590 \\
Red & 630 to 685 \\
Red edge & 690 to 730 \\
Near-infrared & 760 to 850
\end{tabular}

All of the green indices-Green Ratio Vegetation Index (GRVI), Green Normalized Difference Vegetation Index (GNDVI), and Green Atmospherically Resistant Index (GARI) - were strongly correlated at the V2 stage at $75 \mathrm{~cm}$ and considerably outperformed red indices (table 4). This was expected due to the prevailing soil background during early plant growth and was only observed at V2-the earliest growth stage examined. Our results are quite similar to those of Peterson and Baumgardner (1981), who found a strong linear relationship between soil moisture tension and green reflectance between 520 to $580 \mathrm{~nm}$. Although their study was conducted using an indoor spectroradiometer, the wavelengths discussed are nearly the same as the green waveband of the RapidEye satellites used in this study. The relationships at this depth are quite strong, but unfortunately they are not useful for making decisions on how to irrigate given the shallow rooting depth at this early V2 growth stage.

Except for the EnhancedVegetation Index (EVI), the model for NDVI exhibited the 


\section{Figure 3}

Daily precipitation at Colorado State University Agricultural Research Development and Education Center and irrigation amounts in millimeters presented by day of year (DOY) during the 2015 growing season. Vertical dashed lines represent satellite image acquisition days.

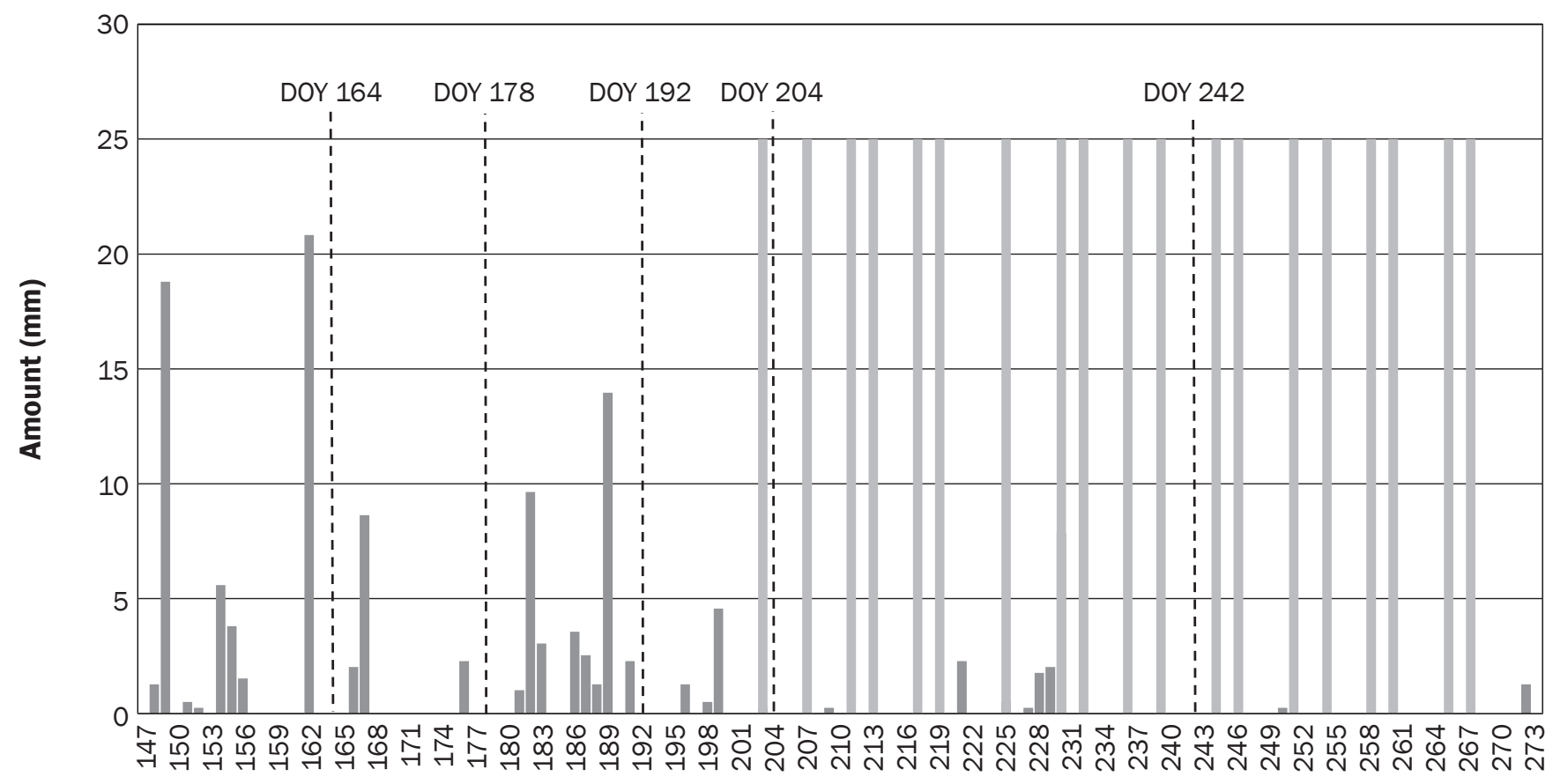

Day of year (DOY)

\section{Legend}

- Precipitation Irrigation

$2.5 \mathrm{~cm}$ of rain fell that week with very little difference between irrigation treatments, which probably masked any variability detectable by means of the spectral response of the plants. The 24-hour and planting to image acquisition intervals likely were not affected as strongly because much less precipitation occurred within each of those intervals as a whole. Furthermore, none of the indices were found to be significant over more than one growth stage. Similar to previously discussed results, GARI and other green indices once again had higher coefficients of determination at V2 stage, 75 $\mathrm{cm}$ deep when compared to the red indices. The positive correlation between soil tension and GARI is very strong. It is notable that the image for this date is comprised mostly of bare soil, which explains the contrast with otherwise negative correlations in all the imagery with considerably more plant growth. Despite statistical significance, these relationships with the green indices are unlikely to have agronomic value at the V2
Table 4

Results from regression analysis of average soil moisture tension (over the 24 hours previous to satellite image acquisition) on selected indices. Only significant results are presented.

\begin{tabular}{lllllc}
\hline $\begin{array}{l}\text { Tensiometer } \\
\text { depth }(\mathbf{c m})\end{array}$ & Index & $\begin{array}{l}\text { Growth } \\
\text { stage* }\end{array}$ & $\boldsymbol{r}^{\mathbf{2}}$ & $\boldsymbol{p}$-value & RMSE (-kPa) \\
\hline 20 & RENDVI & V6 & 0.850 & 0.009 & 4.291 \\
& & V9 & 0.913 & 0.003 & 3.779 \\
& RECI & V6 & 0.850 & 0.009 & 4.280 \\
& & V9 & 0.796 & 0.017 & 5.792 \\
75 & R3 & 0.693 & 0.040 & 11.850 \\
& RENDVI & V2 & 0.691 & 0.040 & 0.698 \\
& NDVI & V2 & 0.830 & 0.012 & 0.517 \\
& GRVI & V2 & 0.834 & 0.011 & 0.512 \\
& GNDVI & V2 & 0.891 & 0.005 & 0.415 \\
& GARI & V2 & 0.669 & 0.047 & 0.723 \\
\hline
\end{tabular}

Notes: RENDVI = Red Edge Normalized Difference Vegetation Index. RECI = Red Edge Chlorophyll Index. NDVI = Normalized Difference Vegetation Index. GRVI = Green Ratio Vegetation Index. GNDVI = Green Normalized Difference Vegetation Index. GARI = Green Atmospherically Resistant Index. EVI = Enhanced Vegetation Index.

*V2, V6, V9, and R3 are the two leaf, six leaf, nine leaf, and milk stages of maize growth, respectively. 


\section{Figure 4}

(a) Soil tension (20 cm depth) averaged over the day previous to image acquisition as a function of Red Edge Normalized Difference Vegetation Index (RENDVI) for V6 and V9 maize growth stages. (b) Soil tension ( $20 \mathrm{~cm}$ depth) averaged over the day previous to image acquisition as a function of Red Edge Chlorophyll Index (RECI) for V6 and V9 growth stages. (c) Average soil tension (20 cm depth) from planting to acquisition date as a function of RECl for $\mathrm{R}_{3}$ growth stage.

(a)

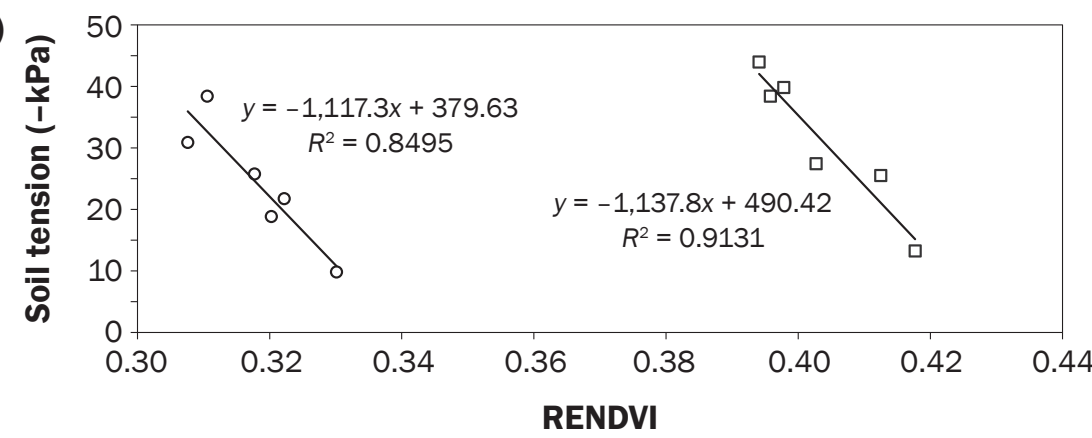

(b)

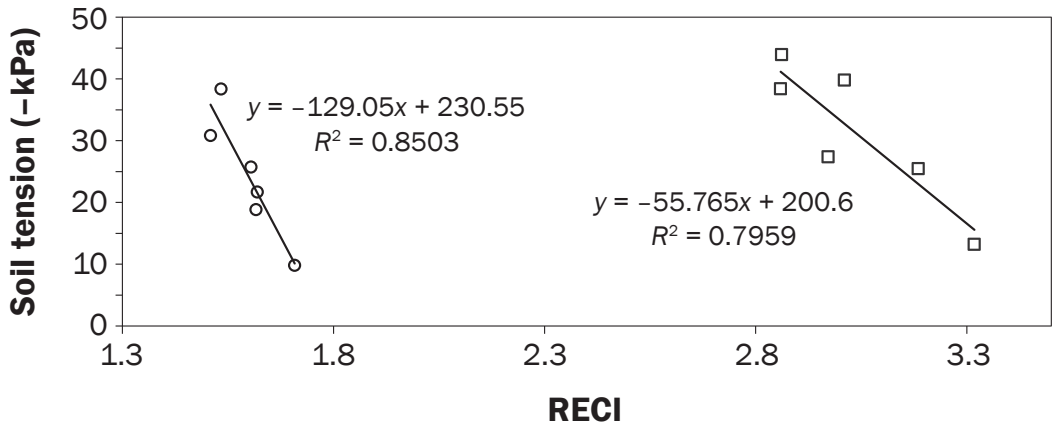

(c)

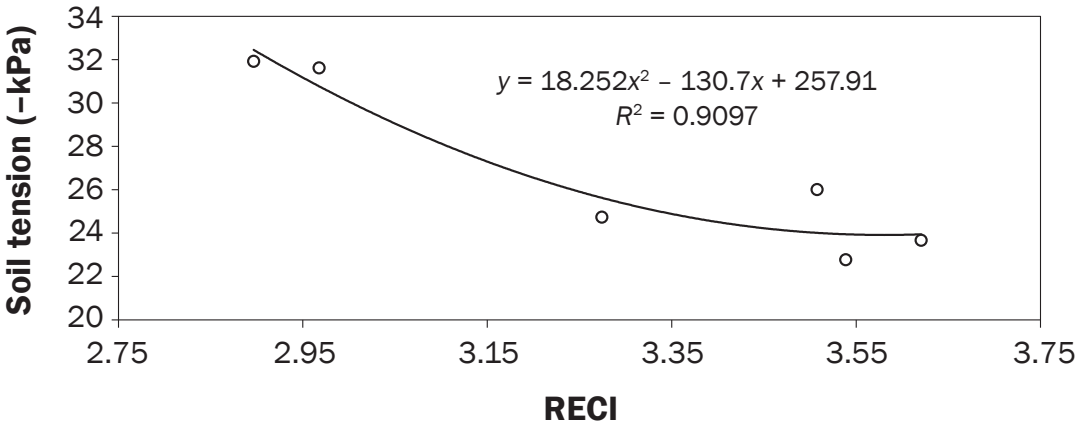

Legend

○ V6 (Six leaf)

口 V9 (Nine leaf) are well correlated, it is important to note that the shape of the quadratic fit, as depicted in figure $4 c$, represents an intuitive trend. The curve in this case levels off at the wettest soil tensions. This is characteristic of excessive irrigation, at which point adding more water fails to benefit the crop and will eventually cause stress.

Bare Ground (Emergence) Image. Data from all three tensiometer depths examined in this study $(20,45$, and $75 \mathrm{~cm})$ indicate that soil surface albedo provides information deeper into the profile than the light can fundamentally penetrate, although the correlations tend to be slightly weaker. For average tension between planting to the image acquisition, RENDVI and RECI produced coefficients of determination above 0.71 at both 20 and $75 \mathrm{~cm}$ depths, while results at $45 \mathrm{~cm}$ were just outside the alpha $=0.05$ significance level. These observations may arise from the combined influence of soil physical properties (e.g., organic matter content, texture, and color), which affect its spectral response and are concurrently related to the behavior of soil when water is introduced (e.g., infiltration rate and water holding capacity).

It was demonstrated that soil reflectance as influenced by water content could be applied amongst contrasting soils if the water content were expressed as soil moisture tension instead of percentage dry mass (Brady 1985). Our results support those findings and also suggest that this can be accomplished at the field scale. Multispectral satellite imagery could then help inform variable rate irrigation systems by accounting for temporal variability at high spatial resolution. Aerial bare soil imagery has been used at field scale to delineate site specific management zones for variable rate nitrogen $(\mathrm{N})$ management (Khosla 2002), but the literature does not include similar studies for variable rate irrigation. Aside from the number of studies (Bowers and Hanks 1965; Idso et al. 1975; Skidmore et al. 1975), which provide evidence that the optical properties of soil vary with water content, our results indeed agree with the suggestion of Campbell (1988) that visible and near-infrared reflectance must also be related to soil moisture tension.

At depths greater than $20 \mathrm{~cm}$, none of the vegetation indices were found to be well correlated with average tension over 24 hours. However, RENDVI and RECI produce moderate correlations (at alpha $=0.1$ ) 


\section{Table 5}

Results from regression analysis of average soil moisture tension (over the week previous to satellite image acquisition) on selected indices. Only significant results are presented.

\begin{tabular}{llllll}
\hline $\begin{array}{l}\text { Tensiometer } \\
\text { depth }(\mathbf{c m})\end{array}$ & Index & $\begin{array}{l}\text { Growth } \\
\text { stage* }\end{array}$ & $\boldsymbol{r}^{\mathbf{2}}$ & $\boldsymbol{p}$-value & RMSE (-kPa) \\
\hline 20 & RDVI & V6 & 0.661 & 0.049 & 5.361 \\
75 & OSAVI & V2 & 0.717 & 0.033 & 0.720 \\
& NDVI & V2 & 0.766 & 0.022 & 0.766 \\
& GRVI & V2 & 0.781 & 0.019 & 0.633 \\
& GNDVI & V2 & 0.784 & 0.019 & 0.628 \\
& GARI & V2 & 0.908 & 0.003 & 0.411 \\
& EVI & V2 & 0.724 & 0.032 & 0.711 \\
\hline
\end{tabular}

Notes: RDVI = Renormalized Difference Vegetation Index. OSAVI = Optimized Soil Adjusted Vegetation Index. NDVI = Normalized Difference Vegetation Index. GRVI = Green Ratio Vegetation Index. GNDVI = Green Normalized Difference Vegetation Index. GARI = Green Atmospherically Resistant Index. EVI = Enhanced Vegetation Index

*V2 and $\mathrm{V} 6$ are the two leaf and six leaf growth stages of maize, respectively.

\section{Table 6}

Results from regression analysis of average soil moisture tension (from planting to satellite image acquisition) on selected indices. Only significant results are presented.

\begin{tabular}{llllll}
\hline $\begin{array}{l}\text { Tensiometer } \\
\text { depth }(\mathbf{c m})\end{array}$ & Index & $\begin{array}{l}\text { Growth } \\
\text { stage* }\end{array}$ & $\boldsymbol{r}^{\mathbf{2}}$ & $\boldsymbol{p}$-value & RMSE (-kPa) \\
\hline 20 & RENDVI & R3 & 0.772 & 0.021 & 2.143 \\
& RECI & R3 & 0.861 & 0.008 & 1.672 \\
& Quadratict & R3 & 0.910 & 0.027 & 1.556 \\
& NDVI & R3 & 0.699 & 0.038 & 2.461 \\
& GRVI & V2 & 0.664 & 0.048 & 1.259 \\
& GNDVI & V2 & 0.657 & 0.050 & 1.271 \\
& RENDVI & R3 & 0.827 & 0.012 & 4.190 \\
& RECI & R3 & 0.851 & 0.009 & 3.891 \\
& RDVI & R3 & 0.754 & 0.025 & 4.992 \\
& OSAVI & R3 & 0.799 & 0.016 & 4.514 \\
& NDVI & R3 & 0.767 & 0.022 & 4.862 \\
& RDVI & V2 & 0.736 & 0.029 & 0.771 \\
& OSAVI & V2 & 0.816 & 0.014 & 0.644 \\
& NDVI & V2 & 0.882 & 0.005 & 0.515 \\
& GARI & V2 & 0.808 & 0.015 & 0.658 \\
& EVI & V2 & 0.729 & 0.023 & 0.729 \\
\hline
\end{tabular}

Notes: RENDVI = Red Edge Normalized Difference Vegetation Index. $\mathrm{RECl}=$ Red Edge Chlorophyl Index. $\mathrm{RDVI}=$ Renormalized Difference Vegetation Index. OSAVI = Optimized Soil Adjusted Vegetation Index. NDVI = Normalized Difference Vegetation Index. GRVI = Green Ratio Vegetation Index. GNDVI = Green Normalized Difference Vegetation Index. GARI = Green Atmospherically Resistant Index. $\mathrm{EVI}=$ Enhanced Vegetation Index.

*V2 and R3 are the two leaf and milk stages of maize growth, respectively.

†Quadratic regression is included because it is more intuitive than the linear model.

at all three depths for one week and planting to image acquisition date tension intervals. This suggests that although immediate soil moisture conditions near the surface are strongly correlated with the spectral response of soil, conditions deeper in the soil profile are only related after a considerable lag is allowed-likely for precipitation to infiltrate to that depth.

These results support the use of bare soil multispectral imagery for characterizing heterogeneous soil moisture conditions. It is important to note that the acquisition time for the larger unmasked image is early in the morning, so the image is particularly dark.
General Discussion. Results from regressions of soil tension on RENDVI and RECI indicate that spectral vegetation indices derived from multispectral satellite imagery are capable of characterizing high frequency soil moisture variability at single time points and at large field scales. Simple linear models had high coefficients of determination at more than one vegetative growth stage (both V6 and V9) at the same $20 \mathrm{~cm}$ depth. For RENDVI, the slopes were also nearly identical between stages, and the increase in the $y$-intercept for V9 growth stage was almost proportional. This consistency suggests that a single satellite image acquisition could be reasonably representative of soil moisture variability over time - at least up to a couple weeks after image acquisition - and may help mitigate issues with temporal resolution for variable-rate irrigation management.

Considerable differences between the models at V6 and V9 growth stages suggest that RECI may indeed reflect immediate soil moisture variability, but also that conditions may not be well represented up to a couple weeks as is the case with RENDVI, which is particularly sensitive to slight change. Conversely, models for RECI do appear to be slightly more representative later in the growing season, once reproductive growth is well underway. The shape of the quadratic curves also suggests that the red edge indices are capable of characterizing the stagnant point where applying more water will not benefit the crop. Models from the R3 crop growth stage indicate that longterm (planting to image acquisition date) soil moisture conditions are also well represented up to $45 \mathrm{~cm}$ deep.

Although additional data points may improve upon the value of the study, it should be noted that the state-of-the-art variable rate irrigation system was used to create variability $(40 \%, 60 \%, 80 \%, 100 \%, 120 \%$, and $140 \%$ ET treatments); adequately measuring the variability required fewer samples. In addition, the variable rate irrigation system application efficiency and accuracy were verified with catch cans. Likewise, to maintain accuracy of water application depth, the treatment zones were three times larger (about $325 \mathrm{~m}^{2}$ ) than the area over which the pivot could accurately adjust the water application depth. This was done to ensure that each treatment completely surrounded the tensiometers within it. Furthermore, soil tension is a physical property that is stable and highly correlated with soil moisture content. 
Moreover, soil tension measurements were repeated every 15 minutes, thus generating a vast amount of data that allowed confirmation of the stability of the data acquired.

\section{Summary and Conclusions}

Multispectral satellite imagery, particularly with a red edge waveband, demonstrates potential for quantifying soil moisture tension variability, and hence could be used for variable rate irrigation management. RENDVI was especially sensitive to soil moisture tension and demonstrated that a single image could be representative of spatial variability up to two weeks after acquisition. However, it is unlikely that multispectral satellite imagery could be used to detect rapid changes in soil moisture. It is necessary to confirm repeatability of these results at more maize growth stages and with other crops. Finally, an economic study to evaluate the monetary and environmental implications of such management at field scale would help transition these findings into industry adoption.

\section{Acknowledgements}

This work was supported by the USDA Natural Resources Conservation Service (NRCS), Colorado State UniversityAgricultural Experiment Station, the Colorado Corn Growers Association, the Fluid Fertilizer Foundation, and FarmLogs.

\section{References}

Adegoke, J.O., and A.M. Carleton. 2002. Relations between soil moisture and satellite vegetation indices in the US Corn Belt. Journal of Hydrometeorology 3(4):395-405.

Allen, R.G., L.S. Pereira, D. Raes, and M. Smith. 1998. Crop evapotranspiration: Guidelines for computing crop water requirements. United Nations Food and Agriculture Organization (FAO), Irrigation and drainage paper 56. Rome: FAO.

Bastiaanssen, W.G., D.J. Molden, and I.W. Makin. 2000. Remote sensing for irrigated agriculture: Examples from research and possible applications. Agricultural Water Management 46:137-155.

Bowers, S., and R. Hanks. 1965. Reflection of radiant energy from soils. Soil Science 100:130-138.

Brady, N. 1985. Advances in Agronomy, Volume 38. New York: Academic Press.

Campbell, G. 1988. Soil water potential measurement: An overview. Irrigation Science 9:265-273.

Carter, G.A., and A.K. Knapp. 2001. Leaf optical properties in higher plants: Linking spectral characteristics to stress and chlorophyll concentration. American Journal of Botany 88: 677-684.

Carter, G.A., and R.L. Miller. 1994. Early detection of plant stress by digital imaging within narrow stress- sensitive wavebands. Remote Sensing of Environment 50:295-302.

Clarke, T.R. 1997. An empirical approach for detecting crop water stress using multispectral airborne sensors. HortTechnology 7:9-16.

Engman, E.T. 1991. Applications of microwave remote sensing of soil moisture for water resources and agriculture. Remote Sensing of Environment $35: 213-226$

Evans, R.G., S. Han, M. Kroeger, and S.M. Schneider. 1996. Precision center pivot irrigation for efficient use of water and nitrogen. In Proceedings of the Third International Conference on Precision Agriculture, June 23-26, 1996, Minneapolis, Minnesota, 75-84. Madison, WI: American Society of Agronomy, Crop Science Society of America, and Soil Science Society of America.

Harris Geospatial Solutions. 2015. Broadband Greenness. http://www.harrisgeospatial.com/docs/ BroadbandGreenness.html.

Idso, S., R. Jackson, R. Reginato, B. Kimball, and F. Nakayama. 1975. The dependence of bare soil albedo on soil water content. Journal of Applied Meteorology 14:109-113.

Khosla, R. 2002. Use of site-specific management zones to improve nitrogen management for precision agriculture. Journal of Soil and Water Conservation 57(6):513-518.

Lea-Cox, J.D. 2012. Using Wireless Sensor Networks for Precision Irrigation Scheduling. London: INTECH Open Access Publisher.

Li, H., R.J. Lascano, E.M. Barnes, J. Booker, L.T. Wilson, K.F. Bronson, and E. Segarra. 2001. Multispectral reflectance of cotton related to plant growth, soil water and texture, and site elevation. Agronomy Journal 93:1327-1337.

Lillesand, T.M., R.W. Kiefer, and J.W. Chipman. 2008. Remote sensing and image interpretation. Hoboken, NJ: John Wiley \& Sons.

Longchamps, L., R. Khosla, R. Reich, and D.W. Gui. 2015. Spatial and temporal variability of soil water content in leveled fields. Soil Science Society of America Journal 79(5):1446-1454.

Neale, C.M., H. Jayanthi, and J.L. Wright. 2005. Irrigation water management using high resolution airborne remote sensing. Irrigation and Drainage Systems 19:321-336

Peterson, J., and M. Baumgardner. 1981. Use of spectral data to estimate the relationship between soil moisture tensions and their corresponding reflectances. Technical Report 143. West Lafayette, IN: Purdue University Water Resources Research Center.

Planet. 2016. RapidEye Imagery Product Specifications. https://www.planet.com/products/ satellite-imagery/files/160625-RapidEye\%20ImageProduct-Specifications.pdf.

R Core Team. 2015. R: A language and evironment for statistical computing. Vienna, Austria: R Foundation for Statistical Computing.
Ritchie, S.W., and J.J. Hanway. 1989. How a corn plant develops. Special Report No. 48. Ames, IA: Iowa State University Cooperative Extension Service.

Sadler, E., R. Evans, K. Stone, and C. Camp. 2005. Opportunities for conservation with precision irrigation. Journal of Soil and Water Conservation 60(6):371-378.

Schaible, G., and M.Aillery. 2012. Water conservation in irrigated agriculture: Trends and challenges in the face of emerging demands. USDA ERS Economic Information Bulletin. Washington, DC: USDA Economic Research Service.

Siegfried, J., R. Khosla, and L. Longchamps. 2017. Infrared thermometry to quantify in-field soil moisture variability. Journal of Crop Improvement 31(1):72-90.

Soil Survey Staff. 1980. Soil Survey of Larimer County, Colorado. USDA Coop. Soil Survey. Washington, DC: US Government Printing Office.

Srinivasan, A. 2006. Handbook of Precision Agriculture: Principles and Applications. Binghamton, NY: Food Products Press.

Western Regional Climate Center. 2015. Climate Summaries. Reno, NV:Western Regional Climate Center. 